\title{
Leadership for safety: industrial experience
}

\author{
R Flin, S Yule
}

Qual Saf Health Care 2004;13(Suppl II):ii45-ii51. doi: 10.1136/qshc.2003.009555

The importance of leadership for effective safety management has been the focus of research attention in industry for a number of years, especially in energy and manufacturing sectors. In contrast, very little research into leadership and safety has been carried out in medical settings. A selective review of the industrial safety literature for leadership research with possible application in health care was undertaken. Emerging findings show the importance of participative, transformational styles for safety performance at all levels of management.

Transactional styles with attention to monitoring and reinforcement of workers' safety behaviours have been shown to be effective at the supervisory level. Middle managers need to be involved in safety and foster open communication, while ensuring compliance with safety systems. They should allow supervisors a degree of autonomy for safety initiatives. Senior managers have a prime influence on the organisation's safety culture. They need to continuously demonstrate a visible commitment to safety, best indicated by the time they devote to safety matters.

See end of article for authors' affiliations

Correspondence to: Professor R Flin, Industrial Psychology Research Centre, University of Aberdeen, King's College, Old Aberdeen AB24 2UB, UK; r.flin@abdn.ac.uk

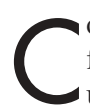
oncern about patient safety has tended to focus attention almost exclusively on the unsafe behaviours of frontline staffmistakes, omissions, and rule violations labelled as active failures or human error. While workers' activities at the operational level of an organisation will certainly be the proximal cause of adverse events, it is also necessary to understand the distal, causal factors (enacted by the humans managing the organisation at the tactical and strategic levels). These are variously called latent conditions ${ }^{1}$ or organisational factors-they create the safety culture that influences the probability of the sharp end or proximal failures. ${ }^{23}$ Investigations into major accidents in the energy sector in the 1980s revealed that a key organisational factor in maintaining safety in high risk industries is the quality of management. In the inquiry into the loss of the Piper Alpha oil platform (167 fatalities), Lord Cullen ${ }^{4}$ stated,

\section{"No amount of detailed regulations for safety improvements could make up for deficiencies in the way that safety is managed by operators [oil companies]." (p 301)}

Similarly, the investigation into the Chernobyl accident in the nuclear power industry showed that deficiencies in the safety culture of the organisation were to blame. A prime component of the safety culture relates to management commitment to safety and how this is demonstrated to the workforce ${ }^{5-7}$ However, it was not until the 1990s that safety researchers began to divert their attention from an almost exclusive focus on worker behaviour to examine the behaviours of managers, with a particular interest in the leadership component of their role. ${ }^{8} 9$ There is an interminable debate on the definition and conceptual overlap between manager and leader. For the purpose of this article, leadership is taken to encompass the skills relating to influencing a group to attain particular organisational goals. The objective of this paper is to review the research on leadership and safety, focusing on results that may be particularly relevant to safety in health care. Table 1 summarises the main leadership behaviours for safety.

There is an extensive literature on managers' leadership behaviours, which concentrates on organisational outcomes relating to productivity, profit, and turnover..$^{11}{ }^{12}$ Notwithstanding intuitive appeal and slogans that "good safety is good business", the tenet that productivity and safety results are influenced by similar leadership behaviours remains unproven. Drawing on theories from the business leadership literature, industrial psychologists began in the 1990s to test the particular relationship between managers' leadership behaviours and safety outcomes (often called safety leadership). Very little research into leadership and safety has been carried out in medical settings, therefore this paper provides a selective review of the industrial research for possible application in the healthcare sector. Three caveats need to be considered when reviewing the literature, as follows.

Firstly, with the exception of flightdeck studies, $^{13} 14$ most research on leadership and safety is from the energy or manufacturing sectors of industry. In this case, safety means the safety of the workforce on the plant (or a remote public who are at risk from a nuclear release or plant explosion). In health care, safety applies not only to the workforce (who in the UK actually suffer quite significant rates of injury),,$^{15}$ but also to the patients who may be damaged by the actions of the workers. In the absence of any contradictory evidence, it is proposed that the antecedent causes of patient injury and worker injury stem from a common source-hospital safety climate. Hospital safety climate influences

Abbreviations: OIMs, offshore installation managers 
Table 1 Leadership behaviours for safety

\begin{tabular}{lll}
\hline & Transactional behaviours & Transformational behaviours \\
\hline Supervisors & $\begin{array}{l}\text { Monitoring and reinforcing workers' safe } \\
\text { behaviours } \\
\text { Participating in workforce safety activities } \\
\text { (can also be transformational) }\end{array}$ & $\begin{array}{l}\text { Being supportive of safety } \\
\text { initiatives } \\
\text { Encouraging employee involvement in } \\
\text { safety initiatives }\end{array}$ \\
Middle managers & $\begin{array}{l}\text { Becoming involved in safety initiatives } \\
\text { (can also be transformational) }\end{array}$ & $\begin{array}{l}\text { Emphasising safety over productivity } \\
\text { Adopting a decentralised style } \\
\text { Relaying the corporate vision for safety to } \\
\text { supervisors }\end{array}$ \\
Senior managers & $\begin{array}{l}\text { Ensuring compliance with regulatory } \\
\text { requirements } \\
\text { Providing resources for a comprehensive } \\
\text { safety programme }\end{array}$ & $\begin{array}{l}\text { Demonstrating visible and consistent } \\
\text { commitment to safety } \\
\text { Showing concern for people } \\
\text { Encouraging participatory styles in } \\
\text { middle managers and supervisors } \\
\text { Giving time for safety }\end{array}$ \\
\hline $\begin{array}{l}\text { These behaviours have been drawn from the empirical research reviewed in this paper and classified according to } \\
\text { transactional/transformational leadership theory. }\end{array}$ & \begin{tabular}{l}
10 \\
\hline
\end{tabular}
\end{tabular}

worker safety behaviours, via a set of motivational factors, including outcome expectancies, personal values, and peer influences. ${ }^{76}$ Unsafe worker behaviours include errors, rule violation, risk taking, and not reporting incidents. These behaviours are directly linked to two types of failures: negative patient safety outcomes, operationalised as adverse events (for example infection, wrong drug, and wrong blood) and injuries to heathcare workers (for example needlestick injuries and infection). Similar arguments for common pathways have been proposed for product quality and worker safety in industry. ${ }^{17}$

Managers and supervisors have both direct and indirect effects on workers' behaviours. The indirect effects relate to the establishment of norms relating to practices and procedures, thus creating a particular safety culture. The direct effects relate to managers' and supervisors' modelling of safe and unsafe behaviours and to their reinforcement of subordinates' behaviour through monitoring and control. Both directly and indirectly these leader actions influence workers' expectations and motivation, thus influencing the likelihood of particular behaviours (for example rule violation) being repeated or suppressed..$^{18}{ }^{19}$ Through this proposed mechanism, the intermediate variable is workers' safe or unsafe behaviours-and the latter may cause injuries to workers or damage to patients or both.

Secondly, it is acknowledged that the organisational structures and cultures typical of industrial workplaces do not match those of healthcare organisations. ${ }^{20}$ This would appear to be particularly apposite when the question of leadership is examined. In an industrial setting there are, of course, both formal and informal leaders. But on a power plant, if one asks a team or a department "who is the leader?", an unequivocal response is normally given. In a hospital, the formal leadership hierarchy is less well defined. Our experience interviewing operating theatre staff suggests that several people may believe they actually hold the leadership role in a given team $\left(\mathrm{also}^{21}\right)$. An NHS Trust Chief Executive may be in a less powerful position than certain influential members of subordinate professional groups, such as physicians. ${ }^{22}$ To study leadership in the healthcare sector, analyses of power bases ${ }^{23}$ or location of opinion formers ${ }^{24}$ may be required to identify the actual leaders rather than the nominal leaders. Despite this leadership identity crisis in health care, we have employed a conventional level of analysis approach to examine leadership in industrial research, namely a subdivision into three organisational strata:
- operational-the first line supervisor or team leader

- tactical-the department or unit head

- strategic-the senior manager, CEO.

This distinction is important; the roles and responsibilities of leaders are very different depending on their position in the organisational hierarchy. Thus, lists of desirable leader behaviours that do not define the role of the leader in question or stipulate whether these behaviours have proven safety outcomes may be less than useful. Andriessen ${ }^{25}$ concluded that while supervisors are a decisive factor in the safety behaviour of the workforce, it is management that set the supervisor's goals, objectives, and priorities. Thus, higher level management may have a greater degree of influence on workers' safety behaviour than supervisors. He argues that even if direct supervision does not place a high priority on safety, workers may still work safely when higher management stresses safety.

Thirdly, the high levels of attention to leadership skills in selection, training, and competence assessment in industry may not be typical of the healthcare sector.

There are many leadership theories ${ }^{11} 12$ that could be applied to healthcare. One of the dominant theories in current leadership research is Bass and Avolio's $\mathrm{s}^{10}$ model of transformational leadership. This model has been selected as a framework for this paper because several recent studies have examined the role of transformational leadership in safety performance with promising results and it has already been identified by other psychologists as suitable for health care. $^{26}$ Transformational leadership has an appealing theoretical underpinning in eliciting safety performance because effective transformational leaders encourage employees to subscribe to group and organisational goals in preference to immediate personal gain.

\section{TRANSFORMATIONAL LEADERSHIP}

Multifactor, or more commonly transformational leadership theory, ${ }^{10}{ }^{27}$ was developed from earlier work on charisma in political leaders. It postulates three component styles of leadership: transformational, transactional (both explained below), and laissez-faire (doing nothing; abdicating the leadership role). These can be measured using the 45 item Multifactor Leadership Questionnaire, available in self-report and upward appraisal formats (http://www.mindgarden. com). The relationship between transactional and transformational leader behaviours and performance is shown in fig 1. 


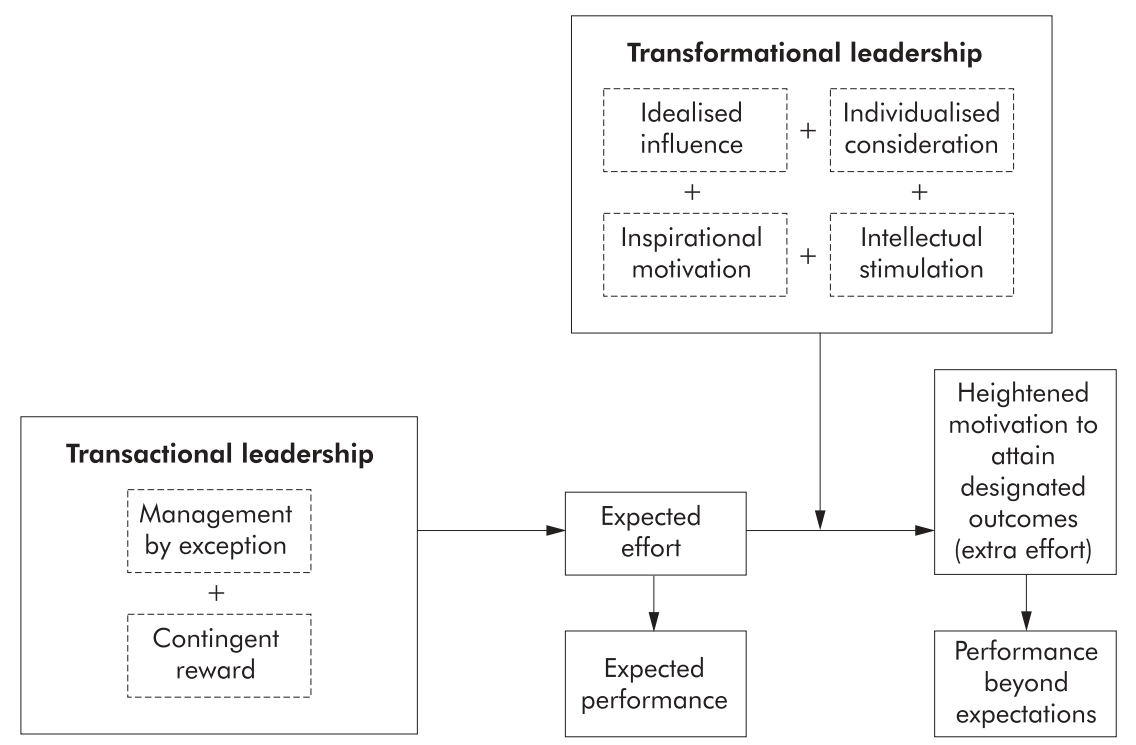

Figure 1 The augmentation effect of transformational on transactional leadership (Adapted from Bass and Avolio, p 237). ${ }^{28}$

The theory conceptualises the basis of all leadership as a transactional relationship between leader and follower. The leader offers a number of incentives and/or punishments that are contingent on the subordinate's performance meeting agreed standards. These may be set out either contractually or informally implied. Transactional leaders gain compliance from followers; set goals; get agreement on what is to be accomplished; monitor performance; and administer reinforcement accordingly. Bass and Avolio argue that this transactional relationship between leader and subordinate will, at best, produce expected performance levels, because it only appeals to individual goals and aspirations. ${ }^{28}$ All leaders use the transactional component in their daily interactions with subordinates; however, according to Bass and Avolio, only leaders of the highest performing teams display transformational behaviours in addition to transactional behaviours.

Transformational leaders are charismatic, inspiring, stimulating, and considerate. They provide followers with a sense of purpose; portray an image of success, self confidence, and self belief; articulate shared goals, mutual understanding, and an attractive future. Transformational leaders question traditional assumptions and encourage others to approach problems from many different angles. They do all this while taking into account the level of maturity, capabilities, and needs of subordinates by treating employees as unique individuals. Fig 1 shows how transformational leadership builds on transactional leadership in what is called the augmentation effect. Effective use of transformational behaviours can motivate subordinates to set aside personal goals and adopt the espoused goals of the group or organisation. This motivates subordinates to extra levels of effort and therefore can improve performance beyond expected levels. While the theory is not without its critics, ${ }^{12}$ Bass and Avolio $^{10}$ have produced a body of evidence that transformational leadership is positively related to subordinate performance, satisfaction, and commitment, and explain unique variance in these outcome variables, over and above that explained by transactional leadership.

\section{SUPERVISORS}

These are the first line managers, called supervisors, foremen, or team leaders in industry. In health care, these would equate to leaders (at an operational level) of established groups, such as ward sisters or leaders of more temporary groups such as an operating theatre team. ${ }^{29}$ Over 40 years ago, Heinrich ${ }^{30}$ advised,

"The supervisor or foreman is the key man in industrial accident prevention. His application of the art of supervision to the control of worker performance is the factor of greatest influence in successful accident prevention." $(p 22)^{30}$

Supervisors have primary responsibilities for achieving the task and maintaining the wellbeing of the team. As they structure, coordinate, and facilitate work activities, both transactional and transformational leadership behaviours are very relevant at this level of management. Zohar ${ }^{18} 19$ has shown by using careful worksite observations and monitoring in manufacturing that when supervisors are encouraged to talk more about safety (transformational) and this is reinforced (transactional), then safety behaviours, such as wearing protective equipment, improve.

Several recent studies have also examined the effectiveness of transformational leadership as a supervisory style for safety. For example, Barling et $a l^{31}$ found that transformational leadership of supervisors was positively related to employee safety behaviour in the hospitality sector. Moreover, they showed that transformational leadership may play a different role in encouraging safety behaviours depending on the motivational state of the team member, and have the most positive impact with individuals who are less committed to safety. Employee perceptions of transformational leadership are predictive of their perceptions of safety climate, which in turn predict unit injury records. ${ }^{31}{ }^{32}$ In a study that did not use a measure of transformational leadership but revealed consistent findings, Hofmann and Morgeson $^{33}{ }^{34}$ found that the quality of communication between supervisors and team members was significantly related to employees' safety commitment and lower accident rates in manufacturing. This result was mediated by safety climate. Several studies have found that the most effective supervisors had a more supportive style of leadership, initiated discussions about safety, and provided positive feedback on safety issues. ${ }^{35-37}$ More participative relationships enable workers to help shape safety interventions rather than simply playing a passive role as recipients. 
Cohen and Cleveland ${ }^{38}$ compared 42 manufacturing and heavy industry worksites in North America with different accident rates. They concluded that employees work more safely when they are involved in decision making processes; when they have specific and reasonable responsibilities, authority and goals; and when they have immediate feedback about their work. Indeed, decentralised management at all levels is not only the best predictor of workgroups' propensity to safety initiatives, it is also the most important factor in relation to two other predictors of worker motivation to behave safety, namely workgroup cohesion and cooperation. ${ }^{39}$ Cooperative relationships are characterised by a positive team spirit and a willingness to cooperate with other team members, other teams, and with management.

As mentioned above, in some healthcare settings teams are formed on a temporary basis to undertake particular tasks such as resuscitations. In this case there may be less clarity as to who is the designated leader and when this happens team performance can be degraded.$^{40}$ Davies has pointed out that, leadership in an operating theatre may need to switch between the anaesthetist and the surgeon during the course of a case. ${ }^{41}$ This clearly requires a very good shared understanding of roles and responsibilities to avoid two leaders or worse, no leader. There has been very little medical research into leadership and safety under these conditions but it would appear to be an important aspect of safety management. Of particular relevance for leaders of acute healthcare teams working in risky, high time pressure conditions are the studies and personal accounts of incident commanders, who have responsibility for managing teams in emergencies. ${ }^{42-44}$

\section{MIDDLE MANAGERS}

There has been less empirical research on the role of the middle manager (department, or site leader) in workplace safety; however, the evidence suggests that the behaviour of middle managers is crucial for high safety performance. Studies comparing low $v$ high accident plants have shown that on the safest sites, managers demonstrate their commitment to the organisation's safety systems and are involved in safety activities. ${ }^{9}$ Their leadership style also seems to influence safety results. Kivimaki et $a l^{45}$ found in the nuclear industry that participative management (that is, more communication and feedback) and time spent by management at the worksite were associated with better safety performance. Likewise, Smith et $a l^{46}$ found that management on low accident rate plants seemed to have a greater level of one to one interaction with their employees, while in higher accident rate plants, management more often relied on committees for communication.

Certainly in high hazard workplaces, site managers are aware of the challenges facing them in maintaining safety standards. O'Dea and Flin ${ }^{47}$ surveyed 200 offshore installation managers (OIMs) in charge of 157 production platforms and drilling rigs in the UK oil industry. They found that while the OIMs acknowledged that a participative leadership style was best practice for safety leadership, the majority actually reported using more directive (telling/selling) styles. More experienced OIMs and those with participative leadership styles seemed to be more aware of the difficulties of getting workers to accept ownership of safety and to report near misses. In another study on offshore platforms, ${ }^{48}$ worker perceptions of OIMs' commitment to safety influenced both workers' compliance with rules and involvement in safety activities. If the managers had a more transformational leadership style, workers reported more safety initiative behaviours. Transactional leadership style did not show any effects.

In terms of direct effects, middle managers can demonstrate their commitment to safety by prioritising safety over productivity-when these goals conflict, becoming involved in safety initiatives and reinforcing supervisors' safety activities. Participative, transformational leadership styles seem to be more effective for safety management. Middle managers must also determine how the corporate vision for safety as espoused by senior managers is relayed to supervisors. Anecdotal evidence indicates that the vision and genuine desire for safety are not often lacking from senior management, rather it is suspected that those sentiments are not passed effectively down the management chain to supervisors and the workforce.

\section{SENIOR MANAGERS}

The most senior managers (for example CEO or Director of Operations) tend to be located away from operational activities; their responsibilities are at a strategic level, such as long range planning. However, they are ultimately accountable for their organisation's safety performance, with increasing legal consequences for proven failure. ${ }^{49}$ In relation to empirical safety research, they have been a neglected species. ${ }^{51}$ However, legal scrutiny ${ }^{49} 52$ and emerging research findings underline the important influence that senior management have on safety performance. Senior managers can demonstrate their commitment to safety by developing and providing resources for a comprehensive safety programme, showing concern for people, encouraging participatory styles in middle managers and supervisors, being clear and consistent in their support for safety, and displaying transformational behaviours.

The higher individuals are in an organisation, the greater their potential to influence organisational outcomes. Decisions made at senior levels affect the priorities, attitudes, and behaviours of managers and employees lower down the organisational hierarchy, and are a critical driver on the emphasis that first line managers place on the competing values of safety and productivity.

\section{"Senior management commitment is crucial to a positive health and safety culture. It is best indicated by the proportion of resources (time, money, people) and support allocated to health and safety management and by the status given to health and safety." (p 46)}

The nuclear industry ${ }^{53}$ advises that senior managers should frequently emphasise the importance of safety.

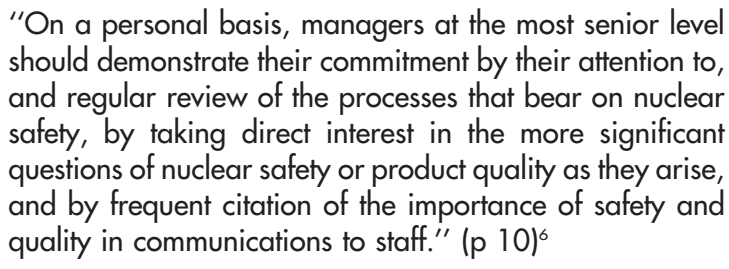

Although the safety regulators promote the value of senior management commitment to safety in reducing accidents and case studies ${ }^{52} 5455$ have often revealed senior mismanagement of safety, there is limited evidence to show exactly which behaviours are most effective. ${ }^{56}$ Investigating the leadership style of senior managers, Yule ${ }^{57}$ reported that leaders in the UK energy sector who were seen as transformational (rated by their subordinates/direct reports) led business units with significantly lower injury rates. In particular, he found that stimulating, individually considerate, and rewarding styles were particularly influential for safety. In a subsequent study using qualitative research techniques he identified a number of critical senior management behaviours for safety. These included articulating an 
attainable vision of future safety performance; demonstrating personal commitment to safety symbolically; engaging everyone with relevant experience in decision making, and being clear and transparent when dealing with safety issues. Similarly, appraisals of transformational leadership in senior managers in an oil company were associated with stronger perceptions by their subordinates of senior management commitment to safety. ${ }^{58}$

Senior managers' prioritisation of safety against other business drivers is clearly important. A survey of 70 European chemical and petrochemical companies ${ }^{59}$ found that only $23 \%$ reported that top management placed safety as a first consideration against other managerial responsibilities. Corporate risk and finance managers from large UK companies showed that they placed most emphasis on ensuring statutory compliance with government health and safety regulations and on the avoidance of legal liabilities. ${ }^{60}$

Evidence from Canada suggests that in top performing firms, occupational health and safety are not viewed as separate functions but as an integral part of productivity, competitiveness, and profitability. Safety and profit are therefore not incompatible goals, but are seen in some companies as complementary because they share similar drivers, and integration is the key. ${ }^{61}$ In contrast, in the majority of companies managers see themselves as having to balance the competing requirements of safety and productivity/profitability, which means that trade off decisions may be required. ${ }^{62}$ This view is endorsed by major accident case studies that reveal that pressure to maintain production was implicated in the causation chain..$^{5563}$ Dangerous practices can be tacitly encouraged by management even though they contradict formal safety policies. ${ }^{65}{ }^{66}$ In order to improve the standard of corporate responsibility for safety, it is necessary to raise the level of safety awareness of those who are in positions to give greater prominence to the place of safety on the corporate agenda. Managerial attitudes such as low fatalism, high safety priority, and high risk awareness have also been shown to be particularly important, ${ }^{67}$ as has trust in senior managers. ${ }^{45}$ If management commitment to safety is important at all levels, then it is necessary for organisations to gather diagnostic data on how this is perceived by those reporting to these leaders. This can be carried out across the organisation using a safety climate survey, and at a managerial level using an upward appraisal technique. Both of these techniques are used in the energy sector ${ }^{51}$ and could easily be adapted for use in healthcare settings. The National Patient Safety Agency (NPSA) have now identified this as a key research topic in their research and development strategy by stating the need for "at NHS board and senior management level, research to understand how safety can best be promoted through leadership". $(\text { p } 12)^{68}$

\section{DISCUSSION}

The purpose of this paper was to review the literature on leadership and safety in order to highlight possible applications to health care. There are few studies of safety leadership in health care, so it is necessary to extrapolate from the studies that have been conducted in other industrial sectors (mainly energy and manufacturing). In those sectors, there is sufficient empirical research on leadership and safety to identify a generic set of effective behaviours at three organisational levels (supervisors, middle managers, senior managers; see table 1). It has already been suggested that transformational leadership may be an appropriate model for improving patient safety in health care $^{26}$ and this paper discusses several studies that apply the transformational/transactional leadership paradigm to safety research. As not all of the studies reviewed use the transformational/ transactional paradigm, table 1 indicates whether the behaviours identified at each management level are transactional or transformational.

In health care, it is likely that transactional behaviours form the basis of relationships between leaders and followers on the wards and in the operating theatres (leaders such as ward sisters, surgeons, anaesthetists). There are several important transactional behaviours that would theoretically be associated with high levels of patient safety. Effective transactional leaders are vigilant and monitor performance. They are therefore able to identify mistakes and deviations from good performance and conditions that may endanger the patients' safety before they manifest as accidents. Another important behaviour for healthcare leaders to engage in is to provide positive verbal feedback for actions (that is, for capturing errors, reporting near misses, speaking up). Communication is vital to maintaining safety performance. ${ }^{33}$ In contrast, leaders who only take action when something goes wrong and do not encourage (or actively discourage) employees to search for mistakes will see their safety performance falter. These transactional behaviours are expected by all leaders on a day to day basis in high reliability/highly safe organisations (of which healthcare centres aspire to), and form the basis for transformational behaviours to build on.

Examining the theoretical rationale for transformational leadership reveals that it is highly applicable to influencing safety performance in health care. This is because transformational leaders encourage employees to subscribe to group and organisational goals in preference to immediate personal gain. As the maintenance of high safety performance is commonly attributed to teamwork and the concept of safety climate emphasises shared goals, ${ }^{69}$ it is feasible that effective transformational leadership could elicit safety performance beyond expectations by transcending personal safety targets and encouraging the buy in of employees to department or organisational level goals. As the core goals of health organisations are patient care and safety, transformational leadership may be an appropriate leadership model for improving patient safety, as long as there are effective exchange based (transactional) relationships to build on. Healthcare leaders can be transformational and improve safety performance by articulating an appealing vision of the future of patient safety, by encouraging members of their team to think for themselves and contribute to the decision making process, and tailoring work to attend to the development needs of individuals. Leaders on the wards and in operating theatres can engage in these behaviours in addition to the transactional, monitoring, and rewarding behaviours suggested earlier. Research in other domains ${ }^{48}$ has found that transformational behaviours have encouraged rule compliance and participation in safety activities by employees. More senior managers must engage in these transformational behaviours in order to set and articulate a vision, strategy, and framework for the future of patient safety in their organisation. It is likely that the balance of behaviours for senior healthcare leaders should be in favour of the transformational behaviours. Senior managers who provide a vision, influence middle managers and supervisors to articulate it, and devolve critical decision making to an appropriate level tended to be found to be associated with the highest safety performing business units. ${ }^{57}$ It is often assumed that leadership ability emerges with seniority, but this is not generally the case in practice, a point illustrated by Donaldson, ${ }^{70}$ "Most health professionals have taken on senior management roles with little training or induction." $(p$ iill). The challenge for health care is to identify and then train the leadership behaviours that will improve patient safety beyond current levels. This paper provides a first step to achieve this 


\section{Key messages}

- Effective leadership has been shown to improve safety performance in high hazard and complex working environments such as aviation, energy, and manufacturing.

- There is little systematic research on leadership and safety in health care.

- Research has identified that different leadership behaviours are effective for safety depending on the level of management studied.

- Transformational and transactional leadership theory may provide a useful model for health care in relation to patient safety.

by presenting evidence of appropriate leadership behaviours for safety from other industries.

\section{Authors' affiliations}

R Flin, S Yule, Industrial Psychology Research Centre, University of Aberdeen

\section{REFERENCES}

1 Reason J. Managing the risks of organizational accidents. Aldershot: Ashgate, 1997

2 Davies J, Ross A, Wallace B, et al. Safety management: a qualitative systems approach. London: Taylor \& Francis, 2003.

3 Flin R, Mearns K. Factoring the human into safety: translating research into practice. In: Wilpert B, Fahlbruch B, eds. System safety. Challenges and pitfalls of intervention. Amsterdam: Elsevier, 2002.

4 Cullen WD. The public inquiry into the Piper Alpha Disaster. London: HMSO.

5 Flin R, Mearns K, O'Connor P, et al. Measuring safety climate: identifying the common features. Safety Science 2000;34:177-192.

6 HSE. Reducing error and influencing behaviour. Suffolk: HSE Books, 1999.

7 Zohar D. Safety climate. Conceptual and measurement issues. In, Quick J, Tetrick L, eds. Handbook of occupational health psychology. Washington, DC: American Psychological Association, 2003:123-42.

8 Hofmann D, Morgeson F. The role of leadership in safety. In: Barling J, Frone $M$, eds. The psychology of workplace safety. Washington: APA Books, 2004.

9 O'Dea A, Flin R. The role of managerial leadership in determining workplace safety outcomes. Health and Safety Executive Research Report RRO44, 2003. http://www.hse.gov.uk/research/rrhtm/rro44.htm.

10 Bass B, Avolio B, eds. Improving organizational effectiveness through transformational leadership. New York: Sage, 1994.

11 Bass B. Bass and Stogdill's handbook of leadership. New York: Free Press, 1990.

12 Yukl G. Leadership in organizations, 5th ed. New York: Prentice Hall, 2002

13 Ginnet R. Crews as groups: their formation and their leadership. In: Weiner E, Kanki B, Helmreich R, eds. Cockpit resource management. San Diego: Academic Press, 1993

14 Fallucco S. Aircraft command techniques. Aldershot: Ashgate, 2002.

15 HSE. Retrieved 1 March 2004, http://www.hse.gov.uk/heathservices.

16 Neale A, Griffin MA. Safety climate and safety at work. In: Barling J, Frone M, eds. The psychology of workplace safety. Washington: APA Books, 2004

17 Herrero SG, Saldaña MAM, del Campo MAM, et al. From the traditional concept of safety management to safety integrated with quality. Journal of Safety Research 2002;33:1-20

18 Zohar D. Modifying supervisory practices to improve sub-unit safety: a leadership-based intervention model. Journal of Applied Psychology 2002a;87:156-63.

19 Zohar D, Luria G. The use of supervisory practices as leverage to improve safety behaviour: a cross-level intervention model. Journal of Safety Research 2003;34:567-77.

20 Gaba D. Structural and organizational issues in patient safety: a comparison of health care to other high hazard industries. California Management Review 2000;43:83-102.

21 Thomas $\mathbf{E}$, Helmreich R. Will airline safety models work in medicine? In: Rosenthal M, Sutcliffe K, eds. Medical error. San Francisco: Jossey Bass, 2002.

22 Sausman C. New roles and responsibilities of NHS chief executives in relation to quality and clinical governance. Qual Saf Healthcare 2001;10(Suppl II):ii 3-ii20.

23 French J, Raven B. The bases of social power. In: Cartwright D, Zander A, eds. Group dynamics, 2nd ed. Evanston, Il: Row \& Peterson, 1960

24 Rogers E. Diffusion of innovations, 5th ed. New York: Simon \& Schuster, 2003.
25 Andriessen J. Safe behaviour and safety motivation. Journal of Occupational Accidents 1978;1:363-76.

26 Firth-Cozens J, Mowbray D. Leadership and the quality of care. Qual Saf Healthcare 2001;10(Suppl II):ii3-ii7.

27 Bass B. Transformational leadership. Mahwah, NJ: LEA, 1998.

28 Bass BM, Avolio B. The implications of transactional and transformationa leadership for individual, team and organizational development. Research in Organizational Change and Development 1990:4:231-72.

29 Edmondson A. Speaking up in the operating room: how team leaders promote learning in interdisciplinary action teams. Journal of Management Studies 2003;40:1419-52.

30 Heinrich H. Industrial accident prevention, 4th ed. London: McGraw Hill, 1959.

31 Barling J, Loughlin C, Kelloway K. Development and test of a model linking safety-specific transformational leadership and occupational safety. Journal of Applied Psychology 2002;87:488-96.

32 Zohar $\mathbf{D}$. The effects of leadership dimensions, safety climate, and assigned priorities on minor injuries in work groups. Journal of Organisational Behavior 2002b;2:75-92.

33 Hofmann D, Morgeson F. Safety-related behavior as a social exchange: the role of perceived organizational support and leader-member exchange. Journal of Applied Psychology 1999;84:286-96.

34 Hofmann D, Morgeson F, Gerras S. Climate as a moderator of the relationship between leader-member exchange and content specific citizenship: safety climate as an exemplar. Journal of Applied Psychology 2003;88:170-8.

35 Mattila $M$, Hyttinen M, Rantanen E. Effective supervisory behaviour and safety on a building site. International Journal of Industrial Ergonomics 1994;13:85-93.

36 Niskanen T. Safety climate in the road administration. Safety Science 1994; 17:237-55

37 Simard M, Marchand A. The behaviour of first line supervisors in accident prevention and effectiveness in occupational safety. Safety Science 1994; 17:169-85.

38 Cohen H, Cleveland R. Safety program practices in record-holding plants. Professional Safety 1983 March:26-33.

39 Simard M, Marchand A. A multilevel analysis of organisational factors related to the taking of safety initiatives by work groups. Safety Science 1995;21:113-29.

40 Marsch S, Muller C, Marquadt K, et al. Human factors affect the quality of cardiopulmonary resuscitation in simulated cardiac arrests. Resuscitation 2004:60:51-6.

41 Davies JM. Report on the pediatric cardiac surgery programme for the pediatric surgery inquiry. Calgary: University of Calgary, 1998

42 Flin R. Sitting in the hot seat. Leaders and teams for critical incident management. Chichester: Wiley, 1986.

43 Flin R, Arbuthnot K. Incident command. Tales from the hot seat. Aldershot: Ashgate, 2002

44 McCann C, Pigeau R, eds. The human in command. New York: Kluwer, 2000

45 Kivimaki K, Kalimo R, Salminen S. Perceived nuclear risk, organizational commitment and appraisals of management: a study of nuclear power plant personnel. Risk Analysis 1995; 15:391-6.

46 Smith $M$, Cohen $H$, Cohen A, et al. Characteristics of successful safety programs. Journal of Safety Research 1978;10:5-15.

47 O'Dea A, Flin R. Site managers and safety leadership in the offshore oil and gas industry. Safety Science 2001;37:39-57.

$48 \mathrm{O}^{\prime}$ Dea A, Flin R. Safety leadership in the oil and gas industry. Paper presented at the Academy of Management Conference. Toronto, August, 2000.

49 Welham M. Corporate killing: the new law. London: Trolley, 2001

50 Forlin G, Appelby M, eds. Corporate lliability. Work related deaths and criminal prosecutions. London: Lexis Nexis, 2003.

51 Flin R. "Danger-men at work": management influence on safety. Human Factors and Ergonomics in Manufacturing 2003;13:261-8.

52 Hopkins A. Lessons from Longford: the Esso gas plant explosion. Canberra Australia: $\mathrm{CCH}, 2000$

53 IAEA. Examples of safety culture practices (safety series no. 1). Vienna: International Atomic Energy Agency, 1997.

54 Carroll J, Hatakenaka S. Driving organizational change in the midst of crisis Sloan Management Review 2001;42:70-9.

55 Hopkins A. Managing major hazards. The lessons of the Moura mine disaster. Sydney: Allen \& Unwin, 1999.

56 Smallman C. The reality of "revitalizing health and safety". Journal of Safety Research 2001;32:391-439.

57 Yule S. Senior management influence on safety in the UK and US energy sectors. PhD Thesis, University of Aberdeen, 2003

58 Bryden R. Getting serious about safety: accountability and leadership-the forgotten elements. In: Proceedings of Society of Petroleum Engineers Health, Safety, Environment conference, Kuala Lumpur, March. (SPE 73940). Texas: SPE, 2002.

59 Keller AZ, Huwaishel AM. Top-management attitude towards safety in the western European chemical and petrochemical industries. Disaster Prevention and Management 1993:2:48-57.

60 Ashby SG, Diacon SR. Motives for occupational risk management in large UK companies. Safety Science 1996;22:229-43.

61 Warrack BJ, Sinah MN. Integrating safety and quality: building to achieve excellence in the workplace. Total Quality Management 1999; 10:S779-85.

62 Dawson S, Willman P, Clinton A, et al. Safety at work: the limits of selfregulation. Cambridge: Cambridge University Press, 1988. 
63 Flin R. Piper Alpha: decision making and crisis management. In: Boin A, Rosenthal U, Comfort L, eds. Managing crisis: threat, dilemmas, and opportunities. Illinois: CC Thomas, 2001.

64 Vaughan D. The Challenger launch decision. Risky technology, culture, and deviance at NASA. Chicago: The University of Chicago Press, 1996.

65 Cutler T, James P. Does safety pay? A critical account of the Health and Safety Executive Document: 'The Costs of Accidents'. Work Employment \& Safety 1996;10:755-65.

66 Nichols T, Armstrong P. Safety or profit. Bristol: Falling Wall Press, 1973.
67 Rundmo T, Hale A. Managers' attitudes towards safety and accident prevention. Safety Science 2003;41:557-74.

68 NPSA. Draft research and development strategy. London: National Patient Safety Agency, 2004

69 Health and Safety Commission. Organising for safety: third report of the human factors study group of ACSNI (Advisory Committee on the Safety of Nuclear Installations). Sudbury: HSE Books, 1993.

70 Donaldson L. Safe high quality health care: investing in tomorrow's leaders. Qual Saf Health Care 2001;10(Suppl II):iii-ii12. 